\title{
Peer tutoring in nursing: Quantitative evaluation of a formalized undergraduate tutoring program
}

\author{
Kari Sand-Jecklin*1, Stacy Huber ${ }^{2}$ \\ ${ }^{1}$ Family/Community Dept, West Virginia University School of Nursing, United States \\ ${ }^{2}$ Adult Health Department, West Virginia University, United States
}

Received: September 9, 2019

Accepted: October 28, 2019

Online Published: November 10, 2019

DOI: $10.5430 /$ jnep.v10n2p55

URL: https://doi.org/10.5430/jnep.v10n2p55

\begin{abstract}
Background and objective: Based on the limited literature, a formalized peer tutoring program was developed at the study institution's School of Nursing to promote the success of academically at-risk students. The evaluation process was designed to guide program improvement as well as to contribute to the available literature related to peer tutoring in programs of nursing. The purpose of this study was to formally evaluate a newly developed formalized peer tutoring program for undergraduate nursing students, to inform other undergraduate nursing programs considering implementing a peer tutoring program.

Methods: The peer tutoring program was evaluated using parallel post-experience surveys for tutors and tutees. Participants also completed a Learning and Studying Strategies Questionnaire, to determine if strategy use differed between the two groups.

Results: There were no statistically significant differences in learning/studying strategies used by tutors and tutees, with both being predominantly superficial strategies. Tutors and tutees evaluated the tutoring program overwhelmingly positively. A few students did make suggestions for improvements in the payment system and suggested making tutoring more widely available. Conclusions: The formalized peer tutoring program is a valuable asset in promoting the academic success of undergraduate nursing students. Minor changes to the program have been made according to student suggestions.
\end{abstract}

Key Words: Peer tutoring, Nursing education, Undergraduate students

\section{INTRODUCTION}

Over the last decade, nursing schools have faced a significant dilemma, given the competing goals of educating an increasing number of nursing students to meet the nation's healthcare needs and maintaining high academic standards, within the additional context of limitations in clinical practicum sites appropriate for undergraduate students. ${ }^{[1]}$ Given these circumstances, it has become increasingly important for nursing programs to employ innovative methods to retain admitted students, and to facilitate student academic success. In the study university, centralized tutoring labs were available for basic science courses, but there was no formalized tutoring program for courses in the nursing curriculum. This paper describes the development and evaluation of a new formalized nursing peer tutoring program at a large mid-Atlantic university from the view of both tutors and tutees.

\subsection{Background}

Peer tutoring has been found to be a successful intervention to aid student learning in the post-secondary environment. However, there are few recent publications related to the process of establishing and evaluating outcomes of peer tutoring

\footnotetext{
*Correspondence: Kari Sand-Jecklin; Email: ksandjecklin@hsc.wvu.edu; Address: Family/Community Dept, West Virginia University School of Nursing, United States.
}

Published by Sciedu Press 
in nursing or healthcare-specific courses, particularly related to learning in the classroom setting. Additionally, there are no "gold standards" for development and implementation of formalized tutoring programs in undergraduate nursing programs. ${ }^{[2]}$

Although the literature is limited, it does support positive outcomes resulting from peer tutoring in health science education programs. One manuscript described outcomes related to implementation of a centralized tutoring program for all health science programs at a large university, reporting positive outcomes, including improved academic performance and student satisfaction. ${ }^{[2]}$ Most of the published peer tutoring manuscripts are program specific, with a significant number of the reported studies found in the medical education literature. Outcomes identified from true peer (students tutoring peers enrolled in the same course) and near-peer (older students tutoring younger students) medical school tutoring programs include improved student tutee exam scores, and high satisfaction of both tutors and tutees with the programs. ${ }^{[3-8]}$ Although all of the reviewed studies reported positive outcomes related to peer tutoring, they varied significantly in terms of policies and procedures.

Within nursing education programs, Blowers and others ${ }^{[9]}$ have described numerous patterns of peer tutoring, including one-to-one, one tutor to two tutees, small group tutoring, and larger group tutoring, and listed potential benefits of each. Two studies described peer tutoring within the community college setting, reporting both improvements in learning and studying strategies, and improved grades and retention rates. ${ }^{[10,11]}$ Additionally, studies by Bryer ${ }^{[12]}$ and Loke ${ }^{[13]}$ confirmed the benefits of formalized peer tutoring programs in baccalaureate nursing programs, reporting enhanced student learning, personal growth, and academic success. As with the programs in the medical education literature, there were variations in the nursing peer tutoring policies and procedures, and some manuscripts described the processes more fully than others did. Additionally, only one study identified tutee or tutor studying strategies ${ }^{[6]}$ and none made comparisons of in tutor and tutee use of study strategies or comparisons of tutor and tutee evaluation of the tutoring programs. This study sought to bridge these gaps in the literature, while evaluating the student perceptions of the newly developed formalized peer tutoring program for students enrolled in School of Nursing courses.

\subsection{Conceptual framework}

Vygotsky's Sociocultural Development Theory suggests that the cognitive development of a learner may be facilitated through social interactions. ${ }^{[14]}$ Central to Vygotsky's theory is the concept of the zone of proximal development (ZPD).
Vygotsky's zone of proximal development undergirds the designed peer tutoring program. Vygotsky posited that the zone of proximal development (the learning capacity of the student) represents the area between the student's current knowledge level and what the student's potential knowledge capacity may be with the help of a more knowledgeable other, such as a tutor. ${ }^{[15]}$ This theory supports the use of cooperative learning strategies and scaffolded learning, such as what occurs during tutoring sessions with tutors who have successfully mastered the course content in the recent past. The goal of the ZPD theory is, through a collaborative learning process, to support the learner, in this case the tutee, to reach towards a higher level in the zone. ${ }^{[14]}$ A tutor, as the more knowledgeable other, can facilitate tutee movement toward the highest learning potential through explaining unclear content, supporting tutee engagement with course content, and preparing students for upcoming examinations. This theory is also consistent with Friedlander and others' perceptions of how medical education can promote learning-going deeper than surface learning, actively engaging, using visual representation, and mental rehearsal. ${ }^{[16]}$

\section{METHODS}

This descriptive and comparative evaluation study included a convenience sample of peer student tutors and tutees who participated in the formalized tutoring program in the School of Nursing at a large Mid-Atlantic university during the 20172018 academic year (spring and fall semesters). The formalized peer tutoring program was developed based on programs cited in the literature, ${ }^{[7,8]}$ as well as a successful, but unpublished, tutoring program in the School of Medicine in our university. Initial courses for which tutoring was offered were those that faculty identified students had most difficulty in successfully completing: Foundations of Nursing, Pharmacology, Medical-Surgical courses, and Critical Care. After approval of the study by the university Institutional Review Board, course coordinators for the courses in which tutoring would be offered were contacted for recommendations of peer tutors, based on both prior performance in the course and perceived communication skills. The tutoring program coordinator contacted potential tutors. Eleven students initially enrolled as peer tutors, and five tutors were added in the spring semester. Tutors were provided an orientation to the tutoring process, tutoring policies and procedures, and resources for tutor use. Specific orientation topics included helping tutees develop a study schedule, assisting in development of learning and studying strategies, and developing test-taking strategies. Tutors also read and signed a tutoring agreement containing the code of ethics set forth by the National Tutoring Association. ${ }^{[17]}$ During the orientation, 
tutors were given a cover letter explaining the study, and were provided a link to the Learning/Studying Strategies Questionnaire. Tutors were not required to participate in the peer tutoring study in order to serve as a peer tutor.

All undergraduate nursing students were made aware of the tutoring availability for the identified classes through a mass email. Qualifications for requesting a tutor included: final grade of $80 \%$ (mid-range $\mathrm{C}$ ) in a prior nursing course, grade of $80 \%$ or lower on a test in a current course, or on recommendation of academic advisor or course faculty. These qualifications were set to ensure that potentially limited tutoring resources (both financial and tutor availability) were made available to the most "at risk" students. Students requested a tutor by emailing the tutoring program coordinator. The tutoring coordinator matched tutors and tutees for the course tutoring was requested. Tutees were sent a Peer Tutor Policy/Procedure document, a cover letter and explanation of the study, and a link to the Learning/Studying Strategies Questionnaire. Students were not obligated to participate in the peer tutoring study in order to receive tutoring. No tutors were assigned more than three tutees during the course of the semester, in order to protect the tutors' own study time.

Tutors and tutees were allowed to meet as frequently as weekly, at a time and place agreeable to both. The frequency limitation was imposed to prevent tutees from becoming overly dependent on tutors for learning and studying. Tutor and tutees were allowed to meet individually or in a small group, if this was agreeable to all parties. Tutors were paid $\$ 10$ per hour by the School of Nursing, and \$3 per session by the tutee-this was suggested by the Medical School Tutoring coordinator to promote tutee commitment to the program. However, no students were denied tutoring due to inability to pay the minor charge. Just prior to the end of each semester, student tutors were sent a link to the Tutor Program Evaluation-Tutor Version. Tutees were sent a link to the Tutor Program Evaluation-Tutee Version.

\subsection{Measures}

Three survey instruments were used for data collection. The Learning and Studying Strategies Questionnaire was a researcher-developed survey that had been used successfully in a previous research study. ${ }^{[18]}$ It asked students to rank the importance/benefit of listed in-class learning strategies, out of class learning strategies, and strategies used in studying with classmates, with a rank of 1 indicating the highest importance (see Tables 1 through 3 for selected options for questions). The forced-choice selection options were based on the literature related to superficial verses deeper/metacognitive strategies. ${ }^{[16,19]}$ The purpose of this tool was to ascertain whether tutees and tutors used similar learning/study strate-

Published by Sciedu Press gies, and whether the preferred strategies promoted primarily superficial/rote learning, or deeper synthesis of content.

Two separate Peer Tutor Program Evaluation Surveys were developed based on questionnaires found in the literature $^{[7]}$-one for tutors and one for tutees. The Tutor survey asked students why they decided to become peer tutors, what the benefits of tutoring have been for them, and how much time they took to prepare for a tutoring session. Additionally, they rated their own tutoring behaviors in a number of areas such as knowledge, clear expression of ideas, questioning and listening to tutees, approaching concepts from alternative viewpoints, use of tutoring resources, and whether sessions enhanced their own knowledge of subject matter. Tutors were also asked about tutee behaviors such as arriving on time, being prepared for the tutoring session, and maintaining a positive attitude. Finally, tutors were asked if they would recommend being a peer tutor to other students, and if they had suggestions about improving the peer tutoring program.

The Tutee-Focused Tutor Program Evaluation Survey asked tutees about the reason they requested a tutor, the benefits they received from tutoring, and the resources the tutor used in tutoring sessions. Tutees were asked parallel questions to the tutor survey in relation to tutor knowledge, clear expression of ideas, questioning and listening to tutees, approaching concepts from alternative viewpoints, and use of tutoring resources. They were also asked about tutor behaviors such as arriving on time and being prepared for the tutoring session, and maintaining a positive attitude. Additionally, tutees were asked to rate their overall satisfaction with the program and to make suggestions for improvement.

It was not possible to conduct reliability assessment for the Learning/Studying Strategies Questionnaire due to the nature of the items. The Cronbach's Alpha analysis for the nondemographic and non-narrative items on the Tutee-Focused Tutor Program Evaluation Survey (seven items) indicated high reliability (.97). Reliability analysis for the TutorFocused Survey items was more complex, as questions that paralleled the Tutee-Focused survey asked both about tutor and tutee behaviors. Reliability analysis of items related to tutor behaviors (four items) was .53 , likely related to low variability among respondents, and low numbers of items contained within the subscale.

\section{RESUlTS}

In total, 24 students received tutoring over the fall semester and 38 students were tutored in the spring. The majority of tutoring requests were made for the Pharmacology course $-59 \%$ of fall and $53 \%$ of spring requests. Not all tutors were assigned a tutee, as for some courses, there were 
few requests for a tutor. Total cost to the School of Nursing for peer tutoring over the two semesters was $\$ 2,600$.

\subsection{Learning and studying strategies questionnaire}

Eleven tutors (69\%) and twenty-seven tutees (46\%) completed the Learning/Studying Strategies Questionnaire. Findings indicated that the most commonly used strategies for in-class learning for both tutors and tutees were taking notes and highlighting important materials on class handouts (see Table 1). The most commonly used strategy for studying outside of class for both groups was highlighting important information in readings or class notes (see Table 2). Least commonly used strategies among both tutors and tutees were creating a visual representation of how pieces of information fit together and relating known information to new information.

Table 1. In-class learning strategy ranking

\begin{tabular}{|c|c|c|}
\hline \multirow{2}{*}{ Strategy } & \multicolumn{2}{|l|}{ Mean Rank } \\
\hline & Tutor $(n=11)$ & Tutee $(n=27)$ \\
\hline Taking Notes & 2.4 & 1.5 \\
\hline Highlighting important Material & 2.9 & 3.2 \\
\hline Ask questions to clarify content & 4.0 & 4.7 \\
\hline $\begin{array}{l}\text { Think of examples to clarify } \\
\text { content or apply to clinical setting }\end{array}$ & 4.2 & 3.9 \\
\hline $\begin{array}{l}\text { Relate information to concepts I } \\
\text { already know }\end{array}$ & 4.5 & 4.6 \\
\hline $\begin{array}{l}\text { Summarize information in my } \\
\text { own words }\end{array}$ & 4.6 & 4.3 \\
\hline $\begin{array}{l}\text { Creating a visual representation of } \\
\text { relationships of concepts }\end{array}$ & 5.6 & 5.9 \\
\hline Read or re-read assigned readings & 5.8 & 5.5 \\
\hline
\end{tabular}

Table 2. Out-of-class study strategy ranking

\begin{tabular}{lll}
\hline \multirow{2}{*}{ Strategy } & Mean Rank & \\
\cline { 2 - 3 } & Tutor (n = 11) & Tutee (n = 27) \\
\hline Highlighting important Material & 3.5 & 4.2 \\
Take notes on readings & 3.7 & 5.9 \\
Summarize notes from text/class & 5.4 & 4.2 \\
Read/re-read assigned readings & 5.8 & 5.5 \\
Review homework/study guides & 6.2 & 5.7 \\
Make up or take practice tests & 6.6 & 6.6 \\
Memorize important information & 6.9 & 5.2 \\
Think of examples to clarify & 7.3 & 8.2 \\
content or apply to clinical setting & & \\
Relate new information to what is & 7.5 & 7.9 \\
known & 7.8 & \\
Study with classmates & 7.9 & 5.8 \\
$\begin{array}{l}\text { Make/use flashcards } \\
\text { Creating a visual representation of }\end{array}$ & 9.5 & 10.2 \\
relationships of concepts & & \\
\hline
\end{tabular}

Both groups tended to study with classmates only before an exam. Most preferred strategies in studying with classmates were similar among both student groups (see Table 3). Preferred strategies included to quizzing each other on facts, and reviewing notes. Least preferred strategies in studying with classmates were also the same for both groups of students: making a diagram to relate studied concepts, and relating new information to what is already known. Independent sample $t$-testing indicated that there were no statistically significant differences in tutor and tutee study strategies.

Table 3. Group study strategy ranking

\begin{tabular}{|c|c|c|}
\hline \multirow{2}{*}{ Strategy } & \multicolumn{2}{|l|}{ Mean Rank } \\
\hline & Tutor $(\mathrm{n}=11)$ & Tutee $(n=27)$ \\
\hline Quiz each other on facts & 3.4 & 2.9 \\
\hline Review homework/study guides & 3.5 & 4.2 \\
\hline $\begin{array}{l}\text { Review content we don't understand } \\
\text { and explain to each other }\end{array}$ & 3.5 & 5.9 \\
\hline Review notes & 3.9 & 3.7 \\
\hline $\begin{array}{l}\text { Paraphrase or summarize } \\
\text { information }\end{array}$ & 5.4 & 6.4 \\
\hline Quiz each other with practice tests & 6.3 & 5.7 \\
\hline Trade notes or summaries for review & 6.6 & 5.3 \\
\hline $\begin{array}{l}\text { Think of examples to clarify content } \\
\text { or apply to clinical setting }\end{array}$ & 6.6 & 5.9 \\
\hline $\begin{array}{l}\text { Relate new information to what is } \\
\text { known }\end{array}$ & 7.2 & 7.1 \\
\hline $\begin{array}{l}\text { Creating a visual representation of } \\
\text { relationships of concepts }\end{array}$ & 8.8 & 8.1 \\
\hline
\end{tabular}

\subsection{Tutor program evaluation survey results}

There were 21 responses to the tutor-focused Tutor Evaluation Survey in the fall and spring semesters. The number of responses is greater than the total number of tutors, as 11 tutors served during both fall and spring semesters, and several completed the evaluation twice, as they had been assigned different tutees each semester. Results indicated the top reasons for becoming a tutor were: wanting to help other students reach their academic goals (91\%); tutoring being a good way to review past materials in preparation for licensure exam (62\%); and being able to list tutoring on their resume (57\%). The most frequently identified benefits from serving as a tutor were: increasing knowledge in the subject matter (81\%); helping to develop teaching skills (67\%); enhancing confidence in his/her own accomplishments (62\%); and increasing interest in academic nursing as a possible career (62\%). Tutors generally prepared for a tutoring session, with $43 \%$ reporting 15-30 minutes of preparation, $24 \%$ reporting greater than 30 minutes of preparation, $19 \%$ reporting less than 15 minutes, and only $14 \%$ reporting no preparation. The vast majority of tutors (86\%) met one-to-one with tutees. All tutors either somewhat agreed or strongly agreed that tutees believed the sessions in being helpful in course success. Tu- 
tors' narrative responses to the question asking what they liked most about the program were that they enjoyed reviewing the course content themselves in order to reinforce their learning (38\%), and they enjoyed being able to help peer students learn and progress in the course (29\%). Responses to what they liked least about the program were related to scheduling (24\%), the difficulty with tutees having to pay the three dollar cash fee for tutoring (10\%), and not having a dedicated tutoring space at the School of nursing (10\%).

\subsection{Tutee survey results}

Twenty tutees responded to the Tutee-focused Tutor Evaluation Survey during the spring and fall semesters. In total, over the two semesters, there were 58 tutees (4 received tutoring over both semesters). Thus, the response rate was $34 \%$. Tutees primarily requesting tutoring due to receiving a lower grade than expected on an exam (90\%), having trouble understanding the course content material (35\%), and to avoid failing a course (35\%). The most frequently identified benefits of tutoring for tutees included: clarifying concepts of course material (95\%); improving exam grades $(80 \%)$; enhancing ability to stay motivated in studying (55\%); discovering new ways of learning course material (55\%); and decreasing stress in preparing for exams (50\%). There was variety in the frequency that tutors and tutees met over the semester. Thirty-five percent reported either weekly meetings or meeting 7 to 10 times during the semester. Other pairs met less frequently, either four to six times (40\%) or one to three times (25\%) during the semester. The vast majority of tutees indicated they were able to meet with their tutor as often as needed (90\%). Overall, 95\% of tutees agreed or strongly agreed that sessions with the tutor were helpful in improving their knowledge of the subject matter. Tutees rated their overall satisfaction with the program very positively, with $95 \%$ of being either somewhat or extremely satisfied. One student had a tutor that did not reply about tutoring sessions. Tutees' narrative responses indicated that what they best liked about the program was that tutors were able to explain/clarify information in a way they could understand $(35 \%)$, tutors helped them with exam preparation (15\%), and that tutors were helpful and approachable (15\%). Tutees, like tutors, least liked the scheduling difficulty (25\%), and the limit in meeting times to once per week (10\%). Program improvement suggestions made by tutees included making tutoring available to more students (10\%), and allowing tutors and tutees to meet more frequently than once per week $(10 \%)$.

\subsection{Comparison of tutor and tutee survey responses}

In comparing responses of tutors and tutees on parallel survey questions, we found that both groups evaluated the parallel survey items positively. Median scores for both groups were 1 (strongly agree) for the tutor being knowledgeable about the subject matter, encouraging the tutee to ask questions and taking time to answer them, and using resources other than textbook to enhance understanding. Both tutor and tutees rated their tutoring partner highly in terms of arriving on time and prepared for the tutoring session, keeping a positive attitude during the tutoring sessions, and the tutoring sessions being helpful, with a median score of 1 (strongly agree). Tutees and tutors differed in their response to only one item - the tutor expressing ideas/concepts clearly. Tutors rated their own ability to express ideas/concepts clearly lower than tutees rated the tutor's ability. Wilcoxon Signed Rank test comparison indicated that this difference was statistically significant $\mathrm{Z}=-1.99, \mathrm{p}=.047$.

\subsection{Limitations}

Study limitations include the convenience sample of students, as well as lack of standardization of the tutoring sessions. Additionally, sample size was small, given the guidelines for students who qualified for peer tutoring (students who were at risk for failure). However, it was the perception of the research team that resources should be spent on students at highest risk for failure, and that the tutor and tutee should individually determine the focus and process of the tutoring sessions. Study results indicated that this might have been appropriate in the tutoring situations. Additionally, actual academic grades/scores were not sought for comparison, as we felt that students might be hesitant to grant researchers access to their test scores. We may seek this information in the future, to further validate the success of the peer tutoring program. However, $80 \%$ of tutees did report improved exam grades as a benefit of tutoring, indicating academic improvement because of tutoring. Finally, the reliability of the Tutee-Focused Tutoring Evaluation Survey was relatively low, particularly in terms of tutee behaviors (three-item scale).

\section{Discussion}

The goals of this study were to begin to fill gaps in the literature related to the benefits of peer tutoring in undergraduate nursing programs, and to provide a formal evaluation for the newly implemented peer tutoring program at our School of Nursing.

In general, results support the findings of other studies in health sciences education programs that both tutors and tutees identified peer tutoring as a beneficial program, and tutees reported improved grades/academic gains as a result of tutoring. ${ }^{[2,7,8,11,12]}$ Tutor-identified benefits, including reinforcing their own knowledge, and improving their teaching 
skills are also supported by the literature. ${ }^{[4]}$ Findings also support the use of Vygotsky's Sociocultural Development theory as a foundation of the peer tutoring program, in that the social interactions between tutor and tutee were found to benefit both, and the tutoring sessions helped tutees to move upward within ${ }^{[7]}$ their zone of proximal development

In advancing the knowledge relating to peer tutoring in nursing, we sought to identify both tutor and tutee preferred learning and studying strategies. Both tutors and tutees tended to rely predominantly on more superficial learning strategies (taking notes and highlighting important information). We had expected to find evidence that tutors, who had excelled academically in the nursing program, would prefer "deeper" learning strategies as they promote learning and academic success, ${ }^{[16,19,20]}$ but we found no significant differences in preferred learning/studying strategies. However, in the Tutee-Focused Tutoring Program Evaluation Survey, tutees identified that tutors clarified concepts of course materials, helped them discover new ways of learning course materials, and explained information in a way they could understand-behaviors that are more reflective of deeper metacognitive strategies. It may be that tutors actually do use these strategies, but perhaps do not consciously reflect on them, or that the Learning and Studying Strategy Questionnaire did not reflect all of the strategies used by tutors and tutees. As a result of these findings, we have developed additional tutor resources that promote more active engagement with class material and deeper learning strategies, and plan to develop some type of orientation for new nursing students about metacognition and study strategies that promote deeper learning.

An unexpected finding was that tutors reported development of teaching skills and increased interest in academic nursing as a potential career as benefits in participating in the program. This is certainly a positive outcome, given the projected shortage of nursing faculty in the near future. ${ }^{[21]}$ Additionally, the finding that most tutors prepared for a tutoring session was relatively unexpected, but it speaks to tutors' dedication to the program and to their assigned tutees.

Both tutors and tutees overwhelmingly evaluated the program positively, and comparisons between tutors and tutees evaluations revealed only one significant difference. Tutors evaluated their own ability to clearly express ideas/concepts lower than tutees evaluated the tutors' ability, perhaps reflecting lack of self-confidence in this relatively new role of tutor. Likely, with additional experience tutors would gain confidence in this area.

Tutor and tutee suggestions for improvement have been taken into consideration. Tutors or tutees can now contact the program coordinator to request meeting more frequently than once a week, if there is a need. Requests will be approved on an individual basis, as the goal is to facilitate ultimate student tutee independence in the program, rather than to provide a long-term "crutch" for learning and studying. We have also made tutoring available to more students by changing the grade criteria for eligibility from earning a "middle C" to earning a $\mathrm{C}$ on either a prior exam in the course or earning a $\mathrm{C}$ in a prior nursing course. This change was based both on tutee suggestion, and on the limited financial impact on the School of Nursing Budget. We also now recommend that student tutors and tutees use an electronic system for payment of the tutee portion of the tutoring sessions, to avoid the difficulty with cash payment. Scheduling conflicts may continue to be an issue, as students are allowed to self-schedule tutoring time; however, tutees are encouraged to contact the program coordinator if scheduling issues are significant enough to request a different tutor. Recently, a student study area has been created at the School of Nursing that could be used for tutoring during regular work office/school hours.

Overall, this study has indicated that a formalized peer tutoring program is beneficial for both tutees and tutors, and that both evaluate the program similarly. Future studies should investigate the impact of peer tutoring programs on attrition due to failure to meet academic standards of the school, as well as conducting a tutoring cost/benefit analysis. Finally, additional investigation into the learning/studying strategies of nursing students may guide faculty in developing pedagogical activities to promote student use of of deeper metacognitive learning strategies.

\section{CONFlicts OF InTEREST Disclosure}

The authors declare that there is no conflict of interest.

\section{REFERENCES}

[1] Kavilanz P. Nursing schools are rejecting thousands of applicants in the middle of a nursing shortage. CNN Money [Internet]. 2018 Available from: https://www.cnn.com/search/?q=nursing+ schools+are+rejecting+thousands+of+applicants+in+t he+middle+of $+a+$ nursing+shortage

[2] Gaughf NW, Foster PS. Implementing a centralized institutional peer tutoring program. Educ Health. 2016; 29: 148-51. PMid:27549655 https://doi.org/10.4103/1357-6283.188773

[3] Bene KL, Gergus G. When learners become teachers: a review of 
peer teaching in medical student education. Fam Med. 2014; 46: 783-7.

[4] Evans DJR, Cuffe T. Near-peer teaching in anatomy: An approach for deeper learning. Anatomical Sciences Education. 2009; 2(227-233). PMid:19753627 https://doi.org/10.1002/ase.110

[5] Morgan KM, Northey EE, Khalil MK. The effect of near-peer tutoring on medical students' performance in anatomical and physiological sciences. Clin Anat. 2017; 30: 922-8. PMid:28726243 https://doi.org/10.1002/ca.22954

[6] Provencio AB, Garcia CM, Roesch J. Peer-to-peer tutoring: reducing failure rates in medical school. Medical Education. 2018; 52: 1183. PMid:30345674 https://doi.org/10.1111/medu.13695

[7] Swindle N, Wimsatt L. Development of peer tutoring services to support osteopathic medical students' academic success. Journal of the American Osteopathic Association. 2015; 115(11): e14-e9. PMid:26501763 https://doi.org/10.7556/jaoa.2015.140

[8] Walker-Bartnick LA, Gerger JH, Kappelman MM. A model for Peer Tutoring in the Medical School Setting. Journal of Medical Education. 1984; 59: 309-15. PMid:6708069 https://doi .org/10.109 7/00001888-198404000-00004

[9] Blowers S, Ramsey P, Merriman C, et al. Patterns of peer tutoring in nursing. Journal of Nursing Education. 2003; 42: 204-11.

[10] Higgins B. Relationship between retention and peer tutoring for at-risk students. Journal of Nursing Education. 2004; 43: 319-21. https://doi.org/10.3928/01484834-20040701-01

[11] Joseph JK. The impact of peer tutoring of nursing students in a community college setting as measured by changes in learning and study strategies and grades.: Capella University; 2009.

[12] Bryer J. Peer tutoring program for academic success of returning nursing students. Journal of the New York State Nurses Association. 2012; 43(1): 20-2.
[13] Loke AJ, Chow FL. Learning partnership-the experience of peer tutoring among nursing students: a qualitative study. Int J Nurs Stud. 2007; 44: 237-44. PMid:16412444 https://doi.org/10.1016/ j.ijnurstu. 2005.11.028

[14] Sanders D, Welk D. Strategies to scaffold student learning. Nurse Educator. 2005; 30: 203-7. PMid:16170261 https ://doi.org/10 .1097/00006223-200509000-00007

[15] Doolittle PE. Understanding cooperative learning through Vygotsky's zone of proximal development. Lilly National Conference on Excellence in College Teaching; Columbia, SC1995. p. 27.

[16] Friedlander MJ, Andrews L, Armstrong EG, et al. What can medical education learn from the neurobiology of learning? Academic Medicine. 2011; 86: 415-20. PMid:21346504 https://doi.org/ 10.1097/ACM. 0b013e31820dc197

[17] National Tutoring Association. Code of Ethics: National Tutoring Association; n.d. [August 15, 2017]. Available from: http: //www.ntatutor.com/code-of-ethics.html

[18] Sand-Jecklin K. The impact of active/cooperative instruction on beginning nursing student learning strategy preference. Nurse Education Today. 2007; 24: 474-80. PMid:17030077 https ://doi.org/ $10.1016 / j$.nedt .2006 .08 .006

[19] Zhoo N, Wardeska JG, McGuire SY, et al. Metacognition: An effective tool to promote success in college science learning. Journal of College Science Teaching. 2014; 43(4): 48-54.

[20] Sinapuelas ML, Stacy AM. The relationship between student success in introductory university chameistry and approaches to learning outside of the classroom. Journal of Research in Science Teaching. 2015; 52: 790-815. https://doi.org/10.1002/tea.21215

[21] American Association of Colleges of Nursing. Nursing Faculty Shortage Fact Sheet. 2017. Available from: http://www . aacnnu rsing.org/Portals/42/News/Factsheets/Faculty-Short age-Factsheet-2017.pdf?ver=2017-07-11-103742-167 